UNRAVELLING LEARNING WITHIN MULTINATIONAL CORPORATIONS

By

\author{
Ayse SAKA-HELMHOUT \\ University of Groningen, \\ Faculty of Management and Organization, \\ Department of International Business and Management, \\ P.O. Box 800, \\ 9700 AV Groningen, \\ The Netherlands. \\ Tel: $+31-50-3635142$ \\ Fax: +31-50-3111004 \\ E-mail: a.saka@rug.nl
}

Forthcoming in the British Journal of Management 2007, 18(3) 


\title{
UNRAVELLING LEARNING WITHIN MULTINATIONAL CORPORATIONS
}

\begin{abstract}
This paper explores the impact of institutional variation on the extent to which subsidiary firms learn from multinational corporations. Learning is conceptualized here as consisting of two aspects: knowledge flow and reinforcement of or change in routines to incorporate the behaviourist assumptions of learning into the international business field. The research is based on in-depth case studies that systematically compare the ways in which parent company knowledge diffuses to Polish, Turkish, Italian and German subsidiary firms in the chemical industry. The findings show that even though firms face the same global pressure to integrate and pursue the same international strategy, their learning outcomes are not the same. There is heterogeneous learning owing to differences in the institutional context of home countries. Where institutional structures are not favourable to learning, the proactive or reactive orientation of actors to identifying future needs and modifying existing schemata, which highlight the importance of human agency, is significant in explaining learning.
\end{abstract}

Descriptors: organizational learning, routines, knowledge flow, multinational corporations, institutional effects, subsidiary initiative 


\section{INTRODUCTION}

Various literatures-particularly organization theory, industrial economics, strategic management, and innovation studies—have addressed the importance of organizational learning for a company's effective performance. However, there have been few studies of the learning process within multinationals (exceptions include Brannen, 2004; Fruin, 1997). The upsurge of interest in this line of research has been on knowledge transfer instead. In fact, knowledge transfer in international contexts, more often than not, has been equated with organizational learning (e.g. Zahra et al., 2000; Macharzina et al., 2001). The tangibles of knowledge transfer have been taken as proxy determinants of organizational learning in an international arena (e.g. Barkema and Vermeulen, 1998). While many of the facilitators of organizational learning such as expatriate management and training are likely to be the same as those for knowledge transfer, we can expect their relative importance to change significantly between the transfer process and the impact of the transferred knowledge on established routines within an organization. Thus, we aim to introduce the behaviourist assumptions of organizational learning to the research on the international firm. This stream of research rests on the assumption that organizations learn when their experience results in behavioural change (Cyert and March, 1963; Greve, 1998). This implies that behaviour is routine-based, history-dependent and target-oriented. The objective of the paper is to explore the extent to which learning is situated in national contexts, i.e. to highlight the impact of institutional variation on learning processes within multinational corporations (MNCs hearafter). We draw on the comparative institutional perspective or 'varieties of capitalism' to highlight the potential significance of the country-of-origin effect on the process of learning. We conceptualize the process of learning as consisting of two aspects, i.e. knowledge flow and the reinforcement of or change in routines, and recognize that changes in knowledge will ultimately be reflected in changes in actions. This distinction is in accordance with Brown and Duguid's (1991), and Lave and Wenger’s (1991) understanding of learning through practice, where 'knowledge flow' represents abstract knowledge or canonical practice, and 'the reinforcement of or change in routines' reflects actual or non-canonical practice. In line 
with Levitt and March (1988), we ascribe to the conceptualization of learning as embedding or encoding of acquired knowledge into routine that guides behaviour.

Organizational learning is defined here as some combination of improving actions (Fiol and Lyles 1985) and acquiring new knowledge (Hedberg 1981), whether it is new products or processes, that is of strategic importance to the multinational firm. Learning is conceptualized as taking place when transferred knowledge—organizational practice such as manufacturing improvement methods and product-related knowledge such as product formulations-is encoded into routines either in the form of reinforcing or changing routines. It reflects the acceptance and approval by employees of a practice that is infused with value (see Selznick, 1957), for employees have to deal with competing belief sets for a period of time until one takes over the other. The specific forms of knowledge flow and enactment in routines collectively constitute the intensity of learning. The transfer of knowledge is referred to here as the direction of knowledge flow that is either two-way between the parent and subsidiary, or one-way from the parent to the subsidiary.

The reinforcement of routine behaviour by acquired knowledge is conceptualized as lower-level learning. We equate lower-level learning with "those activities which add to the knowledge base or firm-specific competences or routines of the firm without altering the nature of their activities" (Dodgson 1993, p. 383). This type of learning tends to lead to the development of some rudimentary associations of behaviours and outcomes, but these usually are short-lived and impact only part of what the organization does. By contrast, higher-level learning refers to the development of new routines by acquired knowledge, which can be seen as a discontinuous process, shifting from a state of rules to a state of no rules. This type of learning is more of a cognitive process than repetitive behaviour, for it is linked to the use of heuristics, skills development and insights, requiring in-depth understanding of past actions rather than unreflective action-taking (Fiol and Lyles 1985) ${ }^{1}$. The difference between the two

\footnotetext{
${ }^{1}$ Fiol and Lyles' conceptualization of learning reflects Argyris and Schön's (1978) idea that there is i) deviation-reducing adaptation that occurs when there is understanding within a given framework reflecting single-loop learning, and ii) deviation-amplifying adaptation that involves the creation of new casual relationships built on a new base of assumptions reflecting double-loop learning. This distinction is
} 
types of learning can be summarized by the distinction between learning efforts directed at simple maintenance or elaboration of existing routines for efficiency and effectiveness versus changing routines for a new orientation to work, which "inevitably involves a clash with existing culture and values” (Hendry et al., 1995, p. 195). ${ }^{2}$

In the following section, we discuss the impact of institutional context on learning to acknowledge the social pressures associated with the diversity in beliefs and practices that can hinder the continuation of a practice, or lead to change in routines. This is followed, in the third section, by the introduction of methodology and empirical setting. The variation in the intensity of learning across the cases is reported in the findings section and the conditions underlying this variation are presented in the discussion section. In the final section, we present an overview of the contribution of the analysis to comparative institutionalism and international business.

\section{THEORETICAL BACKGROUND}

\section{Institutional Context of Learning}

Institutional theory has been widely used for studying knowledge transfer among organizations (DiMaggio and Powell, 1983; Scott, 1995), and in particular within MNCs (e.g. Kostova and Roth, 2002). However, these studies have focused on isomorphic pressures to adopting practices for legitimacy purposes where organizational learning is understood as knowledge flowing across countries in a form abstracted from the historical underpinnings and structural embeddedness of ties. By contrast, comparative institutionalism or 'varieties of capitalism’ (VOC) arguments pay systematic attention to the influence of social institutions (e.g. Hall and Soskice, 2001; Whitley, 1999; Boyer, 1996). Dominant forms of governance, such as the public training system, are seen as shaping different forms of business systems (Whitley, 1999). Managerial co-ordination and work organization within the firm reflect the institutional context in which they are embedded. For instance, Sorge (1991) found that firms in

adapted here to the routine-based account of organizational learning as reinforcement or transformation of routines, for Argyris and Schön's definition refers to individual learning in organizations (see Lähteenmäki et al, 2001; Prange, 1999; Elkjaer, 1999; Crossan et al., 1995)

${ }^{2}$ It is important to note that the two types of learning reflect the nature of change vis-à-vis the existing paradigm within an organization (Crossan et al., 1995). 
Britain and West Germany showed striking differences in their operations due to different societal regimes that distinguished between flexible plants and less flexible, but more productive, plants. Thus when firms extend their operations into new institutional contexts, they are highly likely to adapt their existing structures and cultures. Dissimilarities in institutional structures are likely to lead to levels of learning that vary from country to country. This paper examines the differences in institutional settings between Germany and the UK to highlight the potential variation in the way subsidiaries learn from MNCs located in these settings.

The collaborative form of governance in Germany (Lane 1996; Whitley 1999) encourages and supports co-operation between collective actors. Markets are typically regulated in these societies with entry guided by licensing agreements and alliances between firms, banks and other intermediaries, which lock actors into tightly-knit networks. Labour systems in these economies encourage developing high levels of skills in a cumulative manner (Lane 1996). Employee participation at both the plant and company level is supported by a corporatist system of employee representation and an ownership structure that is highly concentrated in the hands of long-term and strategic actors (Vitols 2001). The long-termist approach is complemented by a highly developed system of vocational education and training creating a technically competent and flexible workforce, and a distinctive pattern of corporate control in which bureaucratic mechanisms are aligned with personal and informal controls (Ferner et al., 2001). The distinctive pattern of control typically takes the form of emphasis on people transfer (see Garnier 1982; Harzing 1999). As Pauly and Reich (1997) argued, German firms prefer to export practices from their domestic facilities and integrate operations closely.

By contrast, British firms operate in compartmentalized forms of governance that discourage co-operation between business partners (Whitley, 1999). Relations between actors are defined as 'arm’s length' and typically adversarial. "The handling of risk is accomplished by highly dispersed shareholding rather than by pooling risk through cross shareholding and collective agreements between producers" (Lane 1997, p. 66). Consequently, the influence of employee interests and business partners on decision-making is low. The British system is also seen as deficient in the area of skill training (Lane 1996). This has negative implications for 
continuous innovation and long-term growth strategies. There is an emphasis on the reduction of agency costs through heavy reliance on formal, legalistic mechanisms to order commercial relationships among transacting parties (Vitols 2001). As competences are not constrained by obligational ties to partners, they tend to be more mobile across national borders. In order to manage risk and uncertainty, firms in compartmentalized institutional settings are more willing and able than firms in collaborative governance systems to move assets across sectors and gain experience of managing diverse activities (Whitley, 2001). Foreign subsidiaries of such firms can develop distinctive capabilities quickly as they are not constrained by high levels of MNC control (Otterbeck, 1981). As Almond et al. (2005, p. 281) argue, “'innovation’ [taken to mean practices that are unfamiliar in the host context] may be easier in less actively regulated business and employment systems”.

Against this background, the article investigates the extent to which organizational practice and product-related knowledge is learnt by the Polish, Turkish, German and Italian subsidiaries of German and British MNCs. It examines the institutional settings of MNCs to assess the extent to which organizational learning - the direction of knowledge flow and the reinforcement of or change in routines at subsidiaries—reflects institutional elements specific to the country-of-origin. There is an attempt to consider the contextual embeddedness of knowledge in its link to action.

\section{METHODOLOGY}

The research draws on systematic comparative case studies of two large MNCs in the chemical industry, headquartered in Germany and the UK, and operating in Italy, Germany, Poland, and Turkey. Each case was selected to produce contrasting results for predictable reasons (cf. Yin 2003). There was an attempt in the study to maximize diversity in terms of institutional contexts and economic development of countries. Subsidiaries were theoretically selected on the basis of their manufacturing rather than marketing activities, presence in both developing and developed countries, and the difference in institutional context between the home and host country. Polar cases were chosen so that the learning process was 'transparently 
observable’ (Eisenhardt, 1989). The compartmentalized governance form of the UK contrasted with the collaborative governance form of Germany and the state-organized governance form of Italy (excluding industrial clusters), Poland and Turkey (see Whitley, 1999, for the relevant typologies).

A direct comparison of learning processes across developing and developed countries was not possible in the study, for the British MNC had a marketing operation in Turkey, and an insignificant manufacturing operation of small volume in Italy. Thus, the two significant manufacturing operations of the British MNC-German and Polish-were compared with the Turkish, Polish and Italian subsidiaries of the German MNC.

The research examined the institutional influences on the transfer of organizational knowhow such as manufacturing improvement processes and product-related knowledge such as formulations that were defined by the MNC as successfully developed and introduced to host countries of concern. There was an explicit effort in the study to focus on technological rather than marketing innovations, for local adaptation in host countries was less likely to be observed in technical properties of a product than in marketing efforts. Similarly, there was an attempt to standardize parameters at the home-country level across MNCs along the lines of size, age, product portfolio in terms of its internationalization, and the type of industry. Both of the MNCs were located in the chemical industry. This industry was significant from the standpoint of high internationalization and innovativeness (see CEFIC, 2001), thus, it lent itself to investigating cross-national incidents of learning. Although there was variation in the types of products manufactured, both MNCs operated a flow-production process. Hence, the industry recipes were similar. More importantly, the companies had both shifted their international strategy in mid1990s from a multidomestic approach to global integration with emphasis on centralization and standardization (Bartlett and Ghoshal, 1989).

\section{Data Collection}

The field study, as can be seen in Table 1, employed 35 open-ended and semi-structured interviews conducted between March 2002 to May 2003 with executives overlooking 
international operations in marketing, manufacturing, HR and R\&D at parent companies and their counterparts at subsidiaries, as well as factory tours and document analyses.

Insert Table 1 about here

Information was sought on the types of practices that were transferred, resources that were made available by the parent company, the role of the parent company in subsidiary's operations, the procedures that were adopted by the parent company for subsidiary team's participation in the development and launch of an innovative product, and the way the product was modified to meet the preferences of the given host market. Factory tours helped compare the type of technology that was transferred to various subsidiaries. All interviews were taped and transcribed. The direction of knowledge flow was measured as one-way where there was diffusion of knowledge from the parent company to the subsidiary alone. The diffusion of knowledge between the parent and subsidiary in both directions constituted two-way flow of knowledge. In line with the theoretical definition of Fiol and Lyles (1985), learning was measured as 'higher-level' where improvement in methods of operating such as an emphasis on accuracy in manufacturing was accompanied by an overall change in rules of operating by a technical change in a product such as the modification of product formulations or involvement in new product development by the subsidiary firm. ${ }^{3}$ Such learning necessitates acceptance by employees, upon perceived value, of the acquired knowledge with little resistance. It takes the form of proactive orientation based upon an anticipation of future needs (Sadler-Smith et al., 2001). 'Lower-level' learning was measured by the absence of an overall change in rules of operating by a technical change, that is by an emphasis on improving methods of operating alone. For instance, one could observe, in instances of lower-level learning, simply an initiation

\footnotetext{
${ }^{3}$ The reinforcement of or change in routines was operationalized as relative to a baseline, i.e. a subsidiary's acquired level of knowledge. The assumption here was that technical changes have the potential to radically shift routines in innovative capability building.
} 
of marketing modification in a product. ${ }^{4}$ Based on Sadler-Smith et al's (2001) conceptualization, such level of learning indicates a passive orientation to change.

Initially, detailed case studies were conducted that captured contextualities in learning. This was followed by a comparison across cases conducted systematically to allow for theoretical generalization. A 'method of difference' was adopted for comparing cases with different intensities of learning (Mill 1974). In other words, an instance of a phenomenon's occurrence was compared with an instance of its non-occurrence to identify 'bundles of conditions' that explained for the variation in outcome. This is a method of elimination based on the "successive exclusion of the various circumstance which are found to accompany a phenomenon in a given instance, in order to ascertain what are those among them which can be absent consistently with the existence of the phenomenon” (Mill 1974, p. 392; see Saka 2003 for a recent application). This method is similar to Eisenhardt's (1989) coupling of within-case data analysis with cross-case patterns for a more sophisticated understanding. It is a process that requires convergence on construct definitions, measures, and a framework for structuring findings to build, what Eisenhardt calls, mid-range theory ${ }^{5}$ that is generalizable across settings.

The reliability of the findings was enhanced by making explicit the procedures that were followed for data collection. These procedures included matters of interview protocol, tape recordings of interviews, and feedback on transcriptions from participants. Within case companies, interview data from a particular work group were checked against responses from another group to validate findings. Similarly, subsidiary and parent company members' accounts were cross-checked against each other. Protocols ${ }^{6}$ incorporating schedules of company visits and members to be interviewed were developed. Interview transcriptions were scanned to identify patterns of lower- and higher-level learning at subsidiary firms, as well as the 'bundles

\footnotetext{
${ }^{4}$ Marketing changes, in comparison to technical changes, are not expected to enhance a firm's innovative capability. By contrast, R\&D changes are expected to redefine rules and norms in the context of innovative capability building within MNC-subsidiary relations.

${ }^{5}$ A mid-range theory is one that is "testable, novel, and empirically valid, but lack[s] the sweep of theories like resource dependence, population ecology, and transaction cost” (Eisenhardt, 1989, p. 547).

${ }^{6}$ The interview protocol served as a checklist detailing all the items to be covered by the case studies for comparability across cases. In addition to including semi-structured questions on learning, it noted the position of the respondent in the company and the duration of the interview.
} 
of conditions' that accounted for the variation in the intensity of learning within international settings.

\section{Research Sites}

\section{British MNC and its subsidiaries}

One of the MNCs in the sample, British Chem (a pseudonym), represented an internationally operating chemical company in the UK dating back to early 1900s. The company concentrated its efforts on producing decorative paint. In the late 1990s, it was under great pressure to achieve the maximum leverage out of a single project, hence it adopted a global approach to operating overseas. The emphasis on global integration brought with it structuration and formalization, particularly in product development. With the closure of laboratories, subsidiaries grew dependent on the UK headquarters for new product ideas.

British Chem started its operation in Germany through its British PLC (a pseudonym) acquisition in 1998 to strengthen its German market position. "The British PLC culture [was] very much driven for cash, milking the business as hard as you can, do not drop a penny...British Chem in that respect is more generous. They give you time to develop” (Dutch managing director at British Chem's German subsidiary). There was no British Chem investment in the first two years of the acquisition. However, in 2001, part of the UK volume was transferred to the German site with the closure of one of the UK manufacturing facilities. The company, then, aimed to deliver the best in class performance.

The Polish site was acquired by British Chem in 1996. This marked a change in management, emphasis on continuous improvement, and the introduction of safety, health and environment (SHE) principles to the Polish subsidiary. The subsidiary had a small R\&D department that was responsible mainly for the local adaptation of parent company formulas.

\section{German MNC and its subsidiaries}

The second MNC was an internationally operating chemical company in Germany (given the pseudonym German Chem) dating back to the late 1800s. The unit on which this study was based produced cleansing agents for domestic use. During the last 10 years, German Chem's 
growth had come, to a large extent, from a very high number of acquisitions, especially in Europe. However, as profitability was below that of its two major rivals, the company had to adopt a global approach in its international strategy in 1995.

German Chem started its operation in Turkey through a licensing agreement in 1956, later to form a joint venture in 1963. As the foreign affiliate gained manufacturing experience and established credibility as a competent and reliable adaptor, it came under the full ownership of German Chem (in 1994). It was, thereafter, assigned more complex tasks such as developing products for local and regional markets.

German Chem's Italian operation, which was established as a greenfield investment in 1935, served as home to one of the three significant R\&D facilities of the parent company outside of Germany. It also represented one of the five main affiliates of the German Chem World (France, Benelux, Spain, Italy, and Germany) that collectively generated about 70 per cent of the MNC's net sales.

The Polish site of German Chem was established in 1931 through a joint venture, later to be fully owned in 1992. It was of similar size to the Turkish subsidiary but was less involved in R\&D efforts of the company as a whole. It predominantly prepared labels for German Chem products and registered them in accordance with the Polish law.

\section{FINDINGS}

The case study findings show that there is variation in the levels of learning at subsidiaries owing to the institutionalized differences in the way MNCs support learning processes. Although the cost-cutting initiatives reflected by the shift to global integration are similar at both MNCs, the intensity of learning differs across subsidiaries. German MNC's efforts to create tight networks of relations in the host country as those in the collaborative governance form of the home country encourage two-way flow of knowledge and changes in routines. It is interesting to note that the direction of knowledge flow and the reinforcement of or change in routines do not necessarily correlate. It is possible for one-way flow of knowledge to change routines resulting in higher-level learning at the subsidiary. Contrary to what is 
commonly purported in international business literature (e.g. Vermeulen and Barkema, 2001), it is not the exposure to ideas through a transfer but adjustment in routines that explains for organizational learning.

\section{Intensity of Learning at British Chem's Subsidiaries}

In spite of its local responsiveness to market differences in terms of packaging and colour range, British Chem mainly exports product ideas and recipes to its European subsidiaries, regardless of whether they are in developed or developing countries. Subsidiaries are responsible for minor changes to the product. "For local development of products, usually that is best done very close to the customer in a local country, you know, you are putting few extra colours on to the colour range or just making a small change to a particular product...We do have a discipline, a template, an operating framework that says what is decided where, which decisions are to be taken locally, regionally, internationally and what things you need to tell people” (research and innovation director, British Chem). The rules, procedures and policies for new product development are standardized and formalized.

I would say probably at the moment the most common trend is for most new products to end up being something that exists somewhere else and transferred into another market...I can think of formulations that have been developed in the UK that have then been sold in Germany or in France. The technology was exported from the UK, picked up by the [German] factory and the laboratory, and then used to develop, produce a product for Germany or France. (R\&D manager, British Chem)

British Chem supports the development of its German operation by transferring manufacturing process improvement know-how through programmes such as the 'paint plant of the future' that emphasizes "best in class performance for SHE, quality, cost and customer service in Europe" (site manager, British Chem). However, it does not emphasize expatriate management or international training to acculturate subsidiary members despite the change in its international 
focus from a multidomestic to a global strategy in 1997. There is one-way flow of knowledge on products and improvements in manufacturing accuracy.

With the [X brand], what we did is that we exported it from the UK. So they [the German subsidiary] took the same range as the UK, and then gradually over a period of time, we formulated a match using their raw materials...They sorted their factory out in terms of their quality. So they are now making it for themselves as well as for Czech and Hungary. (general manager R\&D Europe, British Chem)

However, efforts to change routines by diffusing the $[\mathrm{X}]$ brand to Germany initially met resistance. "Four years ago, when I discussed this with Germany and the UK, they [Germany] asked 'why do you want to launch this when other paints cover well, better than those of the competitors'?” (marketing director at the Polish subsidiary of British Chem). The German subsidiary is not too open to ideas transferred from its parent company owing to the pathdependent behaviour established prior to its acquisition. It assumes a reactive orientation to improving its processes in continuous steps to meet headquarter standards.

Because people used to be independent for 40 years in their history and all of a sudden there comes a parent company, puts a foot on us and says 'we will guide you through some of our standards. We have got company standards that you have to follow'. People see that sometimes as pain. (Dutch managing director at British Chem's German subsidiary)

The German subsidiary adheres to old ways of working rather than redesigning old routines in product development and production processes. Its orientation to reinforcing routines suggests lower-level learning.

The Polish subsidiary displays a similar pattern of learning where product recipe and manufacturing-related knowledge flows one-way from the headquarters to the subsidiary. "All the recipes are owned, in fact, by the UK. So if we want to make changes to the recipes, those need to be approved by the UK. There are people from the UK labs who come here and advice” (marketing director at British Chem's Polish subsidiary). This is related to time and resource constraints such as the size of the R\&D department at the Polish site (head of research lab at 
British Chem's Polish subsidiary). If the Polish site has an idea for a new product, it has the autonomy to prepare its own recipe, discuss its test results with the parent company, and sell the product under the international brand name. The site assumes an active orientation to changing templates for behaviour by, for instance, "co-operating in some projects concerning the future of solvent-borne products in Poland. We are also discussing NPD [new product development] regularly” (Polish R\&D manager at British Chem’s Polish subsidiary). Although the subsidiary is perceived as the least technologically advanced of all players in Poland, and "have probably the smallest and not probably the best equipped $R \& D$ lab..., we could implement this [lowvolume, highly profitable, value-added brands] during the preliminary phase of the launch on the market even without having all the stuff [technical capabilities] locally" (marketing director at the Polish subsidiary of British Chem). Thus, there is room for experimentation at the Polish site. The subsidiary's proactive orientation based upon an anticipation of future market needs suggests higher-level learning. This is also reflected by its ready acceptance of new ideas from the parent company. "They [the Polish subsidiary] are hungry for ideas. This is not to say they do not have good ideas of their own, but they are hungry" (general manager R\&D Europe, British Chem).

In terms of the sophistication in the Polish market now...there was no really major paint company there, the paint companies have gone in and started to grow the market from a value point of view, getting them into colour, bringing innovation into the marketplace...As a market, it has proved really responsive to the innovation...They are responding much more readily than say the Germans did, who have perhaps been stuck in their way. (general manager R\&D Europe, British Chem)

The new practices are implemented as long as they are understood. "I do not think that there is something like a resistance. Maybe bigger issue is to understand. If they understand, they are willing to co-operate. There is not so much resistance. This factory...those people care about their work. They are very committed. One of the reasons is that this is a factory in a village and the only job they can get is in the factory” (marketing director at the Polish subsidiary of British Chem). 
Strikingly, the wholesale transplant of product ideas to Poland is associated with an overall change in rather than reinforcement of rules of operating at the site as well as the market. The Polish subsidiary's proactive search for ideas at the parent company allows the subsidiary to adapt work to information from the task as it unfolds. As is illustrated below, the company has revised designs and manufacturing processes to lead changes in the industry.

About four years ago, we were looking at different products to launch which would be innovative, different and better than what the competition has got. There were no products...the market at that point in time seemed to be following the way of developing the tinting business...Looking at the UK market, there were suggestions that launching colours would not be a bad idea, because it works in the UK. However, we are afraid of advices of doing something because it works in the UK. So we did not really know which would be the preferred route. (marketing director at the Polish subsidiary of British Chem)

The Polish site was encouraged to launch colours upon observing satisfactory market research results on another imported product that pointed to important benefits to consumers. It was able to recast its strategy and values sufficiently radically to raise its rank to second position in the marketplace.

\section{Intensity of Learning at German Chem's Subsidiaries}

The shift in German Chem's international strategy from a multidomestic approach to one based on home country leadership or global integration in 1995 meant that "[W]hat we have today is an organization where we have local R\&Ds connected by straight lines [rather than dotted lines] to the headquarters” (strategic planning director at German Chem). In the context of this shift, the MNC offers cultural training that is focused entirely on tearing down national borders. "We are sending people to Germany in the form of job rotation...It may be a short period for training purposes and visits for exchange of experience between headquarters and local units” (R\&D manager at German Chem’s Italian subsidiary). There is heavy emphasis on investing in people. "You invest in a lot of infrastructure, not only machinery and equipment, 
but you build up very much in people, education, training” (corporate VP manufacturing at German Chem). "So you have here [in Germany] more or less the best scientists in the world, you have more or less the best shop floor workers in the world, because of the old German way of learning such as the vocational training” (strategic planning director, German Chem). German Chem tries to ensure that its subsidiaries share the main values of the firm through participation in international management training programmes and Euro-team meetings for new product development. "Now marketing units operate in Euro teams [which consist of a strategic business unit member from the headquarters and marketing managers across Europe]. The Euro team notion is quite important, because everybody is both a local manager and a member of a Strategic Business Unit (SBU) team of that function" (VP market research/business intelligence at German Chem). German Chem holds Euro meetings among its long-established Western European subsidiaries. The Turkish subsidiary is an exception to this sample of participants. The participation of the Turkish site in the strong, tightly-knit network of Euro-team meetings encourages two-way flow of knowledge between the German headquarters and the subsidiary.

We benefit from German Chem’s marketing strategies, guidelines and principles. These are clearly defined by the mother company...There is an emphasis on a common platform in the case of international brands. However, there is also room to modify the marketing mix in circumstances such as an economic crisis. We were allowed to adopt a volume strategy and reduce the price on a premium product during the crisis [in 2001]...We also have the flexibility to modify product formulations including those of international brands. (product manager at German Chem’s Turkish subsidiary)

Crisis management in Turkey means that routines guided by procedures established in advance based on past experience need to be redefined to cope with the constant flux of change. The Turkish site is encouraged to search for solutions of its own to succeed in a chaotic environment. "In some cases, we develop our own formulations by increasing the active ingredients in products to match those of the competitors in the Turkish market" (product manager at German Chem's Turkish subsidiary). Members of the R\&D department can be 
seconded to German headquarters to work on changing product formulations for cost effectiveness or higher product performance. "I was in Germany for 12 months last year to lead a project on re-formulating high-foam washing powder for hand wash. The aim was to outline the technical and financial advantages and disadvantages of using the re-formulated product for the European users. We came to the decision that the European formulation did not introduce cost advantages or higher performance at the same cost level” (product development engineer at German Chem's Turkish subsidiary). The Turkish subsidiary has also changed the product formulation of the purple variant of German Chem's most successful softener in Europe that has been adopted by the MNC's other European operations. Similarly, non-European operations such as Egypt have benefited from the experiences of the Turkish site on, for instance, phosphate-containing products for cost and quality improvements in product development and production (R\&D manager at German Chem's Turkish subsidiary). These exemplify the active orientation that the subsidiary assumes in generating new knowledge through exploration or changing routines that suggests higher-level learning.

The members of the Central Eastern European (CEE) network, led by Austria, to which countries such as Poland, the Czech Republic, Hungary, Romania, and Slovakia belong, are granted less autonomy than those of the Western European (WE) network. One of the reasons for this is as follows:

The five main countries of the German Chem World generate more or less 70 per cent of net sales. This gives you the importance of weight. If I am the bigger country and I have a problem with the blue [variant of a product], even if in all other countries the blue is an interesting concept but there is a problem conceptually in Italy, then the co-ordinator, the steerer will say maybe I need to listen to you more than a country that weighs 5 per cent. (product manager at German Chem’s Italian subsidiary)

The German Chem's Italian operation displays similar results to those found at the Turkish site. "We have the opportunity to participate directly in the work of the German Chem Group, developing new ideas directly. While in the past, it was difficult, because there was not so much freedom to develop ideas directly in Italy, France or Spain” (R\&D manager at German Chem’s 
Italian subsidiary). The subsidiary is able not only to launch marketing changes, such as those in perfumes and colours, but also technical changes as those in the viscosity levels of products.

We worked 10 years ago to re-launch formula with a new raw material. The reason was the bio-degradability of the old raw material. So an international team was established. We were part of this team. First studies were done in Germany. We then worked to adapt the process in Italy, France and Spain...High viscosity was very important for Italy, but not so important for other countries. So we had to find a way to increase the viscosity of the product having the same level of cost as in other countries. We followed a very precise process with specific parameters. The results were then sent to Germany. (R\&D manager at German Chem’s Italian subsidiary)

The German headquarters approved the project upon observing strong test results. Such experimentation and risk-taking at the subsidiary provides the variety and diversity to change routines. It also enables headquarters to benefit from local experiences. This is illustrated by the Italian subsidiary's local experience in physical behaviour of particle sizes in dispersion and shared stress: "We have this kind of experience and facility here, thus had more possibility than colleagues in Germany or in Spain and France to perform trials. We also have experience in [Y brand] softener, because Lomazzo was one of the first plants to produce softeners in the [German Chem] Group” (R\&D manager at German Chem’s Italian subsidiary). This suggests a two-way flow of knowledge between the Italian subsidiary and the parent company.

By contrast to the Turkish and Italian sites, there is no evidence of German Chem's importing of ideas from its Polish subsidiary. Although German Chem has been in operation since 1931 in Poland, its ties are not as strong as those with, for instance, Hungary. "You have always had an economic relationship between Austria and Hungary independent of the [political] regime...History plays an important role as to why we were in Budapest first” (R\&D manager at German Chem's CEE headquarters in Austria). German Chem emphasizes the exporting of marketing techniques and technical tests to Poland. Thus, there is one-way flow of knowledge from the parent to the subsidiary. For instance, "[A] lot of the marketing mix is developed in the headquarters. And the countries are responsible for excellent execution of this 
initiative” (Austrian marketing manager at German Chem's Polish subsidiary). In addition, the Polish subsidiary does not have any responsibility in new product development or technical modification of existing products that can redesign organizational routines for improvements. It is accountable for preparing labels in accordance with the Polish law, registering detergents with the Polish authorities, and performing quality checks on locally-produced goods (R\&D manager at German Chem's Polish subsidiary). According to the headquarters, "there is mismanagement in the company. The company is not run properly. The investment is not there. State-of-the-art product cannot be made. There is good technology and highly skilled people available, but the whole system is totally bankrupt” (corporate VP manufacturing at German Chem). Hence, there is an emphasis on reinforcing routines that suggests lower-level learning at the Polish subsidiary.

The lack of new product development responsibility applies to all of the CEE countries in the German Chem Group.

We [CEE headquarters in Austria] together with the German Chem headquarters develop a formula on paper, then we make a production trial in the CEE country where we want to produce this formula. The local $\mathrm{R} \& \mathrm{D}$ controls the production trial and makes all specification parameters, tests [on density, solubility, the rinsing behaviour]. We have for the development of these products the background and can get insights and know-how from Germany. (R\&D manager at German Chem's CEE headquarters)

The steering role of the Austrian headquarters is as strong today as it was before a name change from German Chem Austria Group to German Chem CEE in 1995. Direct knowledge exchange is still discouraged among CEE subsidiaries: "95 per cent of the communication is always going through Austria [CEE headquarters]. When Romania wants some information from Poland, they are asking us and we are asking Poland” (brand manager at German Chem’s CEE headquarters). A country can come and say it would be interesting to develop for example soap paste, which is still in use in countries like Romania. Then we get a proposal to develop such a product. But they do not develop it in their own country...because you need the background. For example I ask my German colleague if there is such a formula in India, 
China, Egypt...Individual countries could not do this, because they do not know the persons. I know in the headquarters many persons for 17 years and know where they have started....So we [CEE headquarters] have the networking advantage owing to the long history. (R\&D manager at German Chem’s CEE headquarters)

Although the CEE network is strong within itself, it needs to be developed further for two-way flow of knowledge.

\section{DISCUSSION AND CONCLUSIONS}

The findings indicate variation in the intensity of learning in its association with institutional effects. Although the companies have similar international strategies to cope with global pressures for integration (see table 2), they differ in their management of learning processes at subsidiaries. The institutional influences on learning, which point to the contextual embeddedness of knowledge, are highlighted particularly in MNCs' efforts to transfer canonical practices such as marketing and product-related knowledge. However, this transfer does not reveal how knowledge is connected to changes in behaviour or non-canonical practices. The specificity of organizational learning lies in further contextualizing knowledge through its link to encoding what is transferred into routines that guide behaviour. The findings reported here indicate that the motivational disposition to improve processes and change product formulations at subsidiaries, and the mode-of-entry into host country and control exercised over the subsidiary influence the direction of knowledge flow and the impact that acquired knowledge has on reinforcing or changing routines.

The acknowledgement of the routine-based nature of organizational learning in international settings situates learning in the larger context of human action and institutions. Non-canonical descriptions of how subsidiaries resist or readily accept ideas exported from headquarters point out that knowledge is "a complex bundle of situated actions and interpretations aimed at making sense of resources and structures, and maintaining the identity of the members and the working community confronted by both routine and breakdown events" (Patriotta, 2003, p. 37). This is contrary to the common practice in international business studies 
where the tangibles of knowledge transfer are taken as a proxy for organizational learning (e.g. Zahra et al., 2000).

The findings also show that there is not necessarily congruence between knowledge flow and reinforcement of or change in routines. Knowledge that flows one way from the headquarters to the subsidiary can lead to 'higher-level learning' if the subsidiary has an active orientation to generating new knowledge through exploration. This highlights the significance of studying the process of enactment in routines beyond that of knowledge flow. Where there is an interest in highlighting subsidiary learning in terms of a response to mandates from headquarters, one should aim to capture the process of enactment in routines. It is of no surprise for subsidiary initiative to be nurtured by rich and complex communication linkages, and work interdependencies (Bartlett and Ghoshal, 1989) in a context of two-way knowledge flow. What is far more interesting to note, as far as the cases are considered, is that subsidiary initiative can also be elicited through motivational disposition in contexts where communication linkages and work interdependencies are relatively weak.

Table 2 provides an overview of the contextual influences on the intensity of learning across the German, Polish, Turkish and Italian subsidiaries of the British and German MNCs.

Insert Table 2 about here

The institutional effects can be observed in German MNC's heavy emphasis on developing linkages and subsidiary capabilities incrementally. Its subsidiaries are set up as a greenfield investment or a joint venture leading to full ownership over time. These have to reach a certain level of standard to be delegated full responsibility for marketing and technical activities, and for the MNC to import product ideas from them. The characteristic long-term perspective to development in collaborative forms of governance as that in Germany (Lane 2000b) is evident in German Chem's efforts to create tight networks of co-ordination and control. The company emphasizes the acculturation of its subsidiaries through international transfers of managers and international training. This indirect personal form of control (Harzing, 
1999) is particularly evident in the more developed subsidiaries such as those in Italy and Turkey that participate in the WE network of new product development. "In Germany it is common to any manager's task to explicitly transfer or teach their know-how to subsidiaries” (Glunk et al., 1996). The long-termist approach to development is complemented by a highly developed system of vocational education and training in Germany (Ferner et al., 2001).

The tight network of co-ordination and control is also demonstrated by German Chem's organization of Euro-team meetings that serve as integrating mechanisms between the various research teams (cf. Zander and Sölvell, 2000). These meetings socialize local managers into the corporate culture and create a network for the cross-fertilization of ideas between subsidiaries and headquarters (Harzing 2001a). German MNCs are more likely to send out expatriates to their subsidiaries than MNCs from other countries, in particular from the USA and the UK (Harzing, 2001b). The emphasis on expatriate management is evident in German Chem's number of headquarters personnel assigned to various subsidiaries. The company has appointed a marketing manager from the Austrian headquarters to its Polish subsidiary. There is a German Chem member working in the marketing department of the Italian subsidiary, and there are two German expatriates, one of whom is in a general manager role and the other in an engineering role at the Turkish subsidiary. The direct personal mode of control through the use of expatriates (Harzing, 1999) is more noticeable in the less developed Polish site than at the Italian and Turkish subsidiaries. In comparison, despite their recent acquisition (see table 2), British Chem neither has headquarters personnel serving its German and Polish subsidiaries, nor provides technical international training opportunity for its subsidiary members. Rather, it chooses to standardize and formalize rules, procedures and policies to co-ordinate and control activities.

Findings indicate that the German MNC’s attempt “to recreate the model which combines a high-skill work force with a matching organization of technology also in other countries, by undertaking a systematic effort to transform the labour force” (Lane 2000a, p. 203) encourages two-way flow of knowledge and subsidiaries to reframe their existing routines. The collaborative form of governance of the home country and the associated emphasis on tight 
networks of co-ordination and control at host operations do not necessarily lead to lower-level learning at subsidiaries owing to the commitment by the MNC to continuous competence enhancement. German expatriates serve as boundary-spanning individuals in the revision of habitual routines (Tushman and Scanlan, 1981), and actors respond to canonical practices in a proactive manner for higher-levels of learning. This finding goes beyond the 'varieties of capitalism' claim that more organized or 'co-ordinated market economies (CMEs)' like Germany have developed institutions that advantage long-term and incremental innovation strategies (Whitley, 2002; Hall and Soskice, 2001). It highlights processes of learning that are affected by human action and the institutional context in which such processes take place.

By contrast, the deficiency of the compartmentalized governance system in the area of skill training as that in the UK (Lane 1996; Whitley 1999) has negative implications for longterm growth strategy of British Chem. Although British Chem has also shifted its international strategy from multi-domestic to global integration in mid-1990s, it does not attempt, like German Chem, to align its subsidiaries with corporate values. Thus, resistance to ideas transferred from the parent company by particularly the German subsidiary of British Chem may come as no surprise. "The much lesser degree of institutional embeddedness of British firms and their only weak exposure to a consistent and widely obligatory system of institutionalized rule systems [in comparison to German firms], endows firms with greater autonomy but also leaves them far less supported by and implanted in various kinds of networks” (Lane 2000a, p. 195). As the mode-of-entry into Germany and Poland indicate (see table 2), British Chem, in line with the governing principles of 'isolated hierarchies' in compartmentalized national systems, chooses to limit commitment and mutual dependence through acquisitions (Whitley, 1999). Such an institutional context has negative implications for learning at British Chem. This seems to confirm the contention in 'varieties of capitalism' that "capabilities will be less innovative in societies where relations between owners, managers, employees, and firms are adversarial and arm’s length” (Whitley, 1999, p. 82). However, when the motivational disposition of the subsidiary is considered, one notices that capabilities can be innovative indeed. This is illustrated by higher-level learning experienced by the Polish 
subsidiary of British Chem despite similar institutional influences of the home country and the exporting of ideas by the parent company as those experienced by the Germany subsidiary. This is due to the active role that the Polish subsidiary assumes in searching for new product ideas to introduce to the market. By contrast, the German subsidiary responds to product ideas and recipes in a reactive manner that is characterized by caution, inhibition and an aversion to risktaking and experimentation. This highlights the importance of a subsidiary's motivational disposition to seek knowledge (Szulanski, 1996; Gupta and Govindarajan, 2000), and encode it into routines.

It has been argued in the international business field that exposure to diverse ideas in multiple markets creates learning advantages (e.g. Vermeulen and Barkema, 2001; Barkema and Vermeulen, 1998). The case study findings show that it is not the exposure to diverse ideas, which corresponds simply to knowledge transfer, but the commitment to long-term development that leads to learning at subsidiaries. ${ }^{7}$ MNCs can develop relations with subsidiaries incrementally to a level where subsidiary members are granted the autonomy to shape the nature of demands and to redefine the rules and logics operating within a given MNC’s field. Vermeulen and Barkema (2001) further argue that acquisitions 'broaden’ a firm’s knowledge base where differences between acquired and acquiring companies create opportunities for synergies. Similarly, Harrison et al. (1991), and Krishnan et al. (1997) argue that differences between acquired firms and acquiring companies create opportunities for synergies and learning, given that these differences are not too large. Although British Chem's mode-of-entry is an acquisition in both Poland and Germany, the learning benefits are not the same across the two sites. A subsidiary's reactive orientation to parent-company ideas can inhibit any possibility for the diversity in ideas between the acquired and acquiring firm to create learning benefits. This points to the need to observe the links between canonical and noncanonical practices for a more refined understanding of organizational learning within MNCs.

\footnotetext{
${ }^{7}$ Long-term development is indicated here by greenfield investment or a joint venture entry into a host country that comes under full ownership over time, and the exercise of indirect personal mode of control (by socialization and networks) at a subsidiary.
} 
This methodologically-controlled study shows that organizational learning in international settings is more than a process of transferring knowledge. It is rather a routine-based activity that is contextually embedded. To conceptualize learning as knowledge transfer severely limits the role of human agency. Whereas, learning conceptualized in 'agentic terms' highlights actors' recognition, location, and implementation of knowledge in their ongoing and situated transactions. Hence, we reject the notion that organizational learning is simply knowledge flowing across countries in a form that is abstracted from historical underpinnings and structural embeddedness of ties (examples of the advocates of this view, Zahra et al., 2000; Vermeulen and Barkema, 2001). By adopting the behaviourist assumption of learning, we reconcile the two aspects of learning, i.e. knowledge transfer and encoding into routines, for a more refined understanding of the concept within the MNC context. We acknowledge the relationship between the two aspects of learning that generates a wide range of outcomes, from apparent stability to considerable change. Our conceptualization of learning considers that behaviour is constrained and enabled by institutional structures. At the same time, it allows for agency that gives rise to particular patterns of learning. There is variation in intensity of learning across subsidiaries of MNCs from different institutional systems lending support to the 'varieties of capitalism' arguments (Hall and Soskice, 2001; Whitley, 1999). Collaborative forms of governance and the associated 'socialization and network' form of control and mode-of-entry through greenfield investment and full ownership encourage higher-level learning at subsidiaries. Where institutional structures are not favourable to learning, the proactive or reactive orientation of actors to identifying future needs and modifying existing schemata through the incorporation of new knowledge is significant in explaining learning.

Processual accounts of learning that recognize the link between knowledge and action deem more empirical research. The 'alienation' of knowledge transfer from action underscores the need to engage with the study of processes. Such studies require learning to be understood as acquired knowledge grounded in practical consciousness. In addition to having repetitive forms of behaviour, routines encompass effortful accomplishments (Feldman and Pentland, 2003). Such essentially complex patterns of social action can be effectively captured through 
phenomenological studies. Although this research has not adopted a phenomenological approach to studying the highly interactive and contentious nature of learning, it has shed light on the ways in which institutional contexts shape learning patterns, and the link between knowledge flow and the enactment in routines for a more holistic understanding of learning within the MNC context.

This research has attempted to distinguish the routine-based understanding of organizational learning (lower-higher level) from the individual-level perception of learning (single-double loop) in organizations. Future research on MNC learning can further clarify this distinction by building on Feldman and Pentland's (2003) conceptualization of routines as a source of both stability and change. The authors distinguish between the ostensive (abstract pattern such as formal rules and standard operating procedures) and performative (specific actions or improvisatory practices) aspects of routines as an important basis for understanding the internal dynamics of routines. They stress that without these two aspects, a routine cannot produce "repetitive, recognizable patterns of interdependent actions, carried out by multiple actors" (ibid., p. 95). The emphasis here is on organizational routines that are characterized by multiple actors and interdependent actions rather than individual skills, habits, and procedural knowledge (Pentland and Feldman, 2005: 795). Consequently, any future research that adopts a routine-based understanding of organizational learning should focus on artefacts that involve task performance where the tasks are to be performed interdependently by members of multiple groups within an organization (cf. Howard-Grenville, 2005).

Future studies should also highlight not only home-country but host-country effects on international accounts of learning. This would require the standardization of parameters such as size, age and product range of subsidiaries. In considering the product range, the economic development of markets also need to be considered. Furthermore, the manner in which knowledge is disseminated among subsidiaries of an MNC around the world (not just in Europe) can provide insights on organizational learning in international settings. The differences between the European market preferences may not be as pronounced as those between, for instance, South America and Asia. As the general manager R\&D Europe at British Chem 
indicates, "what appeals to people in China and Singapore are very smooth paints for walls. Hence, we were able to take the formulation in South America, transfer it to Asia, use the same formulating techniques, and we had very successful launches of products in Singapore and China based on knowledge that was really gained in South America”. Future research of a larger scope can demonstrate the impact of such disseminations on network-wide learning.

\section{Note}

I extend my gratitude to Prof. Dr. Arndt Sorge for his useful comments on an earlier version of this paper. I would also like to thank the University of Groningen for its generous financial support.

\section{References}

Almond, P., T. Edwards, T. Colling, A. Ferner, P. Gunnigle, M. Müller-Camen, J. Quintanilla, and H. Wächter, (2005). 'Unraveling home and host country effects: An investigation of the HR policies of an American multinational in four European countries', Industrial Relations, 44, pp. 276-306.

Argyris, C. and D. A. Schön (1978). Organizational Learning: A Theory of Action Perspective. Addison-Wesley Publishing, Reading.

Barkema, H. and F. Vermeulen (1998). 'International expansion through start-up or acquisition: A learning perspective’, Academy of Management Journal, 41, pp. 7-26.

Bartlett, C. and S. Ghoshal (1989). Managing Across Borders: The Transnational Solution. Harvard Business School Press, Boston, Massachusetts.

Brannen, M. Y. (2004). 'When Mickey loses face: Recontextualization, semantic fit, and the semiotics of foreigness', Academy of Management Review, 29, pp. 593-616.

Boyer, R. (1996). 'The Convergence hypothesis revisited: Globalization but still the century of nations?'. In: S. Berger and R. Dore (eds), National Diversity and Global Capitalism, pp. 29-59. Cornell University Press, Ithaca.

Brown, J. S. and P. Duguid (1991). 'Organizational learning and communities-of-practice: Toward a unified view of working, learning, and innovating', Organization Science, 2, pp. 4057.

CEFIC (2001). Facts and Figures: The European Chemical Industry in a Worldwide Perspective. The European Chemical Industry Council, www.cefic.org, Brussels.

Crossan, M. M., H. W. Lane, E. W. Roderick and L. Djurfeldt (1995). 'Organizational learning: Dimensions for a theory', The International Journal of Organizational Analysis, 3, pp. 337-360. 
Cyert, R. M. and J. G. March (1963). A Behavioural Theory of the Firm. Englewood Cliffs, Prentice-Hall, New Jersey.

DiMaggio, P. W. and W. W. Powell (1983). 'The iron cage revisited: Institutional isomorphism and collective rationality in organizational fields', American Sociological Review, 48, pp. 147160 .

Dodgson, M. (1993). 'Organizational learning: A review of some literatures', Organization Studies, 14, pp. 375-394.

Eisenhardt, K. M. (1989). 'Building theories from case study research', Academy of Management Review, 14, pp. 532-550.

Elkjaer, B. (1999). 'In search of social learning theory'. In: M. Easterby-Smith, J. Burgoyne and L. Araujo (eds), Organizational Learning and the Learning Organization, pp. 75-91. Sage Publications, London.

Feldman, M. S. and B. T. Pentland (2003). 'Reconceptualizing organizational routines as a source of flexibility and change’, Administrative Science Quarterly, 48, pp. 94-118.

Ferner, A., J. Quintanilla and M. Z. Varul (2001). 'Country-of-origin effects, host-country effects, and the management of human resources in multinationals: German companies in Britain and Spain', Journal of World Business, 36, pp. 107-127.

Fiol, C. M. and M. A. Lyles (1985). 'Organizational learning', Academy of Management Review, 10, pp. 803-813.

Fruin, W. M. (1997). Knowledge Works: Managing Intellectual Capital at Toshiba. Oxford University Press, New York.

Garnier, G. H. (1982). 'Context and decision making autonomy in the foreign affiliates of U.S. multinational corporations', Academy of Management Journal, 25, pp. 893-908.

Glunk, U., C. Wilderom and R. Ogilvie (1996). 'Finding the key to German-style Management', International Studies of Management and Organization, 26, pp. 93-108.

Greve, H. R. (1998). 'Performance, aspirations and risky organizational change', Administrative Science Quarterly, 43, pp. 58-86.

Gupta, A. K. and V. Govindarajan (2000). 'Knowledge flows within multinational corporations’, Strategic Management Journal, 21, pp. 473-496.

Hall, P. A. and D. Soskice (2001). Varieties of Capitalism: The Institutional Foundations of Comparative Advantage. Oxford University Press, Oxford.

Harrison, J. S., M. A. Hitt, R. E. Hoskisson and R. D. Ireland (1991). 'Synergies and postacquisition performance: Differences versus similarities in resource allocations', Journal of Management, 17, pp. 173-190.

Harzing, A.-W. K. (1999). Managing the Multinationals: An International Study of Control Mechanisms. Edward Elgar, Cheltenham.

Harzing, A.-W. K. (2001a). 'Of bears, bumble-bees, and spiders: The role of expatriates in controlling foreign subsidiaries', Journal of World Business, 36, pp. 366-379. 
Harzing, A.-W. K. (2001b). 'An analysis of the functions of international transfer of managers in MNCs’, Employee Relations, 23, pp. 581-598.

Howard-Grenville, J. A. (2005). 'The persistence of flexible organizational routines: The Role of agency and organizational context’, Organization Science, 16, pp. 618-636.

Hedberg, B. (1981). 'How Organizations Learn and Unlearn?'. In: P. C. Nystrom and W. H. Starbuck (eds). Handbook of Organizational Design, pp. 8-27. Oxford University Press, London.

Hendry, C., M. B. Arthur and A. M. Jones (1995). Strategy through People: Adaptation and Learning in the Small-Medium Enterprise. Routledge: London.

Kostova, T. and Roth, K. (2002). 'Adoption of an organizational practice by subsidiaries of multinational corporations: Institutional and relational effects', Academy of Management Journal, 45, pp. 308-324.

Krishnan, H. A., A. Miller and W. Q. Judge (1997). 'Diversification and top management team complementarity: Is performance improved by merging similar or dissimilar teams?', Strategic Management Journal, 18, pp. 361-374.

Lähteenmäki, S., J. Toivonen and M. Mattila (2001). 'Critical aspects of organizational learning research and proposals for its measurement’, British Journal of Management, 12, pp. 113-129.

Lane, C. (1996). 'The social constitution of supplier relations in Britain and Germany: An institutionalist analysis'. In: R. Whitley and P. H. Kristensen (eds), The Changing European Firm: Limits to Convergence, pp. 271-304. Routledge, London.

Lane, C. (1997). 'The governance of interfirm relations in Britain and Germany: Societal or dominance effects?’ In: R. Whitley and P. H. Kristensen (eds), Governance at Work: The Social Regulation of Economic Relations, pp. 62-85. Oxford University Press, Oxford.

Lane, C. (2000a). 'Understanding the globalization strategies of German and British multinational companies: Is a "societal effects” approach still useful?'. In: M. Maurice and A. Sorge (eds), Embedding Organizations, pp. 189-208. John Benjamins Publishing Company, Amsterdam.

Lane, C. (2000b). 'Globalization and the German model of capitalism-erosion or survival?', British Journal of Sociology, 51, pp. 207-234.

Lave, J. and E. Wenger (1991). Situated Learning: Legitimate Peripheral Participation. Cambridge University Press, Cambridge.

Levitt, B. and J. G. March (1988). 'Organizational learning', Annual Review of Sociology, 14, pp. 319-340.

Macharzina, K., M.-J. Oesterle and D. Brodel (2001). 'Learning in multinationals'. In: M. Dierkes, A. B. Antal, J. Child and I. Nonaka (eds), Handbook of Organizational Learning and Knowledge, pp. 631-656. Oxford University Press, Oxford.

Mill, J. S. (1974). A System of Logic Ratiocinative and Inductive: Being a Connected View of the Principles of Evidence and the Methods of Scientific Investigation. University of Toronto Press, Toronto. 
Otterbeck, L. (1981). 'Concluding remarks and a review of subsidiary autonomy'. In: L. Otterbeck (ed), The Management of Headquarters Subsidiary Relationships in Multinational Corporations, pp. 337-343. Gower, Aldershot.

Patriotta, G. (2003). Organizational Knowledge in the Making: How Firms Create, Use, and Institutionalize Knowledge. Oxford University Press, Oxford.

Pauly, L. W. and S. Reich (1997). 'National structures and multinational corporate behaviour', International Organization, 51, pp. 1-30.

Pentland, B. T. and M. S. Feldman (2005). 'Organizational routines as a unit of analysis', Industrial and Corporate Change, 14, pp. 793-815.

Prange, C. (1999). 'Organizational learning-desperately seeking theory?'. In: M. EasterbySmith, J. Burgoyne and L. Araujo (eds), Organizational Learning and the Learning Organization, pp. 23-43. Sage Publications, London.

Sadler-Smith, E., D. P. Spicer and I. Chaston (2001). 'Learning orientations and growth in smaller firms', Long Range Planning, 34, pp. 139-158.

Saka, A. (2003). Cross-national Appropriation of Work Systems: Japanese Firms in the UK. Edward Elgar Publishing Limited, Cheltenham.

Scott, W. R. (1995). Institutions and Organizations. Sage Publications, Thousand Oaks.

Selznick, P. (1957). Leadership in Administration: A Sociological Interpretation. Harper and Row, New York.

Sorge, A. (1991). 'Strategic fit and the societal effect: Interpreting cross-national comparisons of technology, organization and human resources’, Organization Studies, 12, pp. 161-190.

Szulanski, G. (1996). 'Exploring internal stickiness: Impediments to the transfer of best practice within the firm', Strategic Management Journal, 17, pp. 27-44.

Tushman, M. L. and T. J. Scanlan (1981). 'Boundary spanning individuals: Their role in information transfer and their antecedents', Academy of Management Journal, 24, pp. 289-305.

Vermeulen, F. and H. Barkema (2001). 'Learning through acquisitions', Academy of Management Journal, 44, pp. 457-476.

Whitley, R. (1999). Divergent Capitalisms: The Social Structuring and Change of Business Systems. Oxford University Press, Oxford.

Whitley, R. (2001). 'How and why are international firms different? The consequences of crossborder managerial co-ordination for firm characteristics and behaviour'. In: G. Morgan, P. H. Kristensen and R. Whitley (eds), The Multinational Firm: Organizing Across Institutional and National Divides, pp. 27-68. Oxford University Press, Oxford.

Whitley, R. (2002). 'Developing innovative competences: The role of institutional frameworks'. Industrial and Corporate Change, 11, pp. 497-528.

Vitols, S. (2001). 'Varieties of corporate governance: Comparing Germany and the UK'. In: P. A. Hall and D. Soskice (eds). Varieties of Capitalism: The Institutional Foundations of Comparative Advantage, pp. 337-360. Oxford University Press, Oxford. 
Yin, R. K. (2003). Applications of Case Study Research, (2 ${ }^{\text {nd }}$ edition). Sage, London.

Zahra, S. A., R. D. Ireland and M. A. Hitt (2000). 'International expansion by new venture firms: International diversity, mode of market entry, technological learning, and performance', Academy of Management Journal, 43, pp. 925-950.

Zander, I. and Ö. Sölvell (2000). 'Cross-border innovation in the multinational corporation: A research agenda’, International Studies of Management and Organization, 30, pp. 44-67. 
Table 1. Case study Firms

\begin{tabular}{|l|l|l|l|l|l|l|}
\hline Firms & \multicolumn{6}{|c|}{ Number of Respondents } \\
\hline & Headquarters & $\begin{array}{l}\text { German } \\
\text { subsidiary }\end{array}$ & $\begin{array}{l}\text { Polish } \\
\text { subsidiary }\end{array}$ & $\begin{array}{l}\text { Italian } \\
\text { subsidiary }\end{array}$ & $\begin{array}{l}\text { Turkish } \\
\text { subsidiary }\end{array}$ & Total \\
\hline $\begin{array}{l}\text { British } \\
\text { Chem }\end{array}$ & 11 & 2 & 5 & N/A & N/A & 18 \\
\hline $\begin{array}{l}\text { German } \\
\text { Chem }\end{array}$ & 6 & N/A & 5 & 2 & 4 & 17 \\
\hline Total & 17 & 2 & 10 & 2 & 4 & 35 \\
\hline
\end{tabular}


Table 2. Intensity of Learning at Subsidiaries

\begin{tabular}{|c|c|c|c|c|c|}
\hline MNCs & \multicolumn{2}{|l|}{\begin{tabular}{|l|} 
British Chem \\
\end{tabular}} & \multicolumn{3}{|l|}{ German Chem } \\
\hline $\begin{array}{l}\text { Institutional context of } \\
\text { home country }\end{array}$ & \multicolumn{2}{|c|}{ Compartmentalized form of governance } & \multicolumn{3}{|c|}{ Collaborative form of governance } \\
\hline International strategy & \multicolumn{2}{|c|}{$\begin{array}{l}\text { Shift from multi-domestic to global integration in } \\
1997\end{array}$} & \multicolumn{3}{|c|}{ Shift from multi-domestic to global integration in 1995} \\
\hline Knowledge transfer & \multicolumn{2}{|c|}{$\begin{array}{l}\text { Exports product ideas and recipes, as well as } \\
\text { engineering and manufacturing process } \\
\text { improvement know-how }\end{array}$} & \multicolumn{3}{|c|}{ Exports and imports product concepts and formulations } \\
\hline Subsidiaries & Germany & Poland & Poland & Turkey & Italy \\
\hline $\begin{array}{l}\text { Mode of entry into host } \\
\text { country }\end{array}$ & Acquisition (1998) & Acquisition (1996) & $\begin{array}{l}\text { Joint venture in 1931, } \\
\text { full ownership in } 1992\end{array}$ & $\begin{array}{l}\text { Licensing agreement in } \\
\text { 1956, joint venture in } \\
\text { 1963, full ownership in } \\
1994\end{array}$ & Greenfield (1935) \\
\hline Mode of control & \multicolumn{2}{|c|}{$\begin{array}{l}\text { Standardized and formalized new product } \\
\text { development procedures }\end{array}$} & $\begin{array}{l}\text { Use of expatriates to } \\
\text { directly control } \\
\text { subsidiary }\end{array}$ & \multicolumn{2}{|c|}{$\begin{array}{l}\text { Emphasis on strong ‘corporate culture’, } \\
\text { acculturating subsidiaries through international } \\
\text { management training and secondment }\end{array}$} \\
\hline $\begin{array}{l}\text { Motivational disposition } \\
\text { to improving processes } \\
\text { and changing product } \\
\text { formulations }\end{array}$ & $\begin{array}{l}\text { Reactive orientation; } \\
\text { resistance to new ideas }\end{array}$ & $\begin{array}{l}\text { Proactive orientation; } \\
\text { receptivity to new ideas }\end{array}$ & $\begin{array}{l}\text { Reactive orientation; } \\
\text { not a member of a Euro } \\
\text { team for product } \\
\text { development }\end{array}$ & $\begin{array}{l}\text { Proactive orientation; } \\
\text { member of a Euro team } \\
\text { for product } \\
\text { development } \\
\end{array}$ & $\begin{array}{l}\text { Proactive orientation; } \\
\text { member of a Euro team } \\
\text { for product } \\
\text { development }\end{array}$ \\
\hline $\begin{array}{l}\text { Intensity of Learning } \\
\text { (Direction of knowledge } \\
\text { flow and reinforcement } \\
\text { or change in routines) }\end{array}$ & $\begin{array}{l}\text { Lower-level } \\
\text { (One-way flow of } \\
\text { knowledge, } \\
\text { reinforcement of } \\
\text { routines) }\end{array}$ & $\begin{array}{l}\text { Higher-level } \\
\text { (One-way flow of } \\
\text { knowledge, change in } \\
\text { routines) }\end{array}$ & $\begin{array}{l}\text { Lower-level } \\
\text { (One-way flow of } \\
\text { knowledge, } \\
\text { reinforcement of } \\
\text { routines) }\end{array}$ & $\begin{array}{l}\text { Higher-level } \\
\text { (Two-way flow of } \\
\text { knowledge, change in } \\
\text { routines) }\end{array}$ & $\begin{array}{l}\text { Higher-level } \\
\text { (Two-way flow of } \\
\text { knowledge, change in } \\
\text { routines) }\end{array}$ \\
\hline
\end{tabular}


